\title{
КОРПУСНАЯ ЛИНГВИСТИКА КАК СПОСОБ ИЗУЧЕНИЯ ПЕРЕВОДЧЕСКОГО НАСЛЕДИЯ КИРИЛЛА И МЕФОДИЯ
}

\author{
Corpus Linguistics as a Research Method \\ of Cyril's and Methodius's Cultural Heritage
}

\author{
Elena Shimko
}

DOI: 10.17846/CL.2021.14.1.184-193

\begin{abstract}
SHIMKO, Elena. Corpus Linguistics as a Research Method of Cyril's and Methodius's Cultural Heritage. The article analyzes the issues of using the linguistic corpus to research Cyril's and Methodius's cultural heritage and Church Slavonic texts: the text is considered as the main point for analyzing the history of the Church Slavonic language. The author names topical issues for the research of the Church Slavonic language in the area of Slavia Ortodoxa, and demonstrates the possibilities of using corpus linguistics and its methods in the research of ancient and modern Church Slavonic texts. The article substantiates the theoretical and methodological possibility of analyzing linguistic phenomena (based on the text-centric principle) with the methods of corpus language research. The author analyzes the explanatory possibilities of modern text-oriented corpus linguistics and describes the dynamics of the text-centric approach in modern linguistic developments. The methodological connection of linguistics of Church Slavonic discourse with the corpus method of its research is explained.
\end{abstract}

Keywords: Linguistic corpus, Church Slavonic language, Church Slavonic text, cultural heritage of Cyril and Methodius

Церковнославянский язык дан нам в текстах, которые являются общим достоянием всего православного славянства и в течение многих столетий служат основой религиозных и культурных связей разных славянских народов. Именно текст многие историки языка считают основным объектом познания, данным в непосредственном наблюдении: текст является объективной реальностью, с которой имеет дело исследователь. По мнению исследователей, выводы о фактах языка строятся на основании непосредственного наблюдения за каждым конкретным текстом: текст является вполне исчерпывающим объектом познания, наблюдение над которым дает право исследователю делать свои умозаключения о сущности того или иного лингвистического факта.

Изучение переводческого наследия Кирилла и Мефодия - одна из самых старых тем славянской филологии. Изучение церковнославянского языка подразумевает более или менее точное знание того, где и когда определенный текст появился впервые и в каком виде; выяснение всех основных этапов его развития; установление его эволюции в новых переводах, переписях, переделках, редакциях; использовании уже имеющихся вариантов. Иными словами существует необходимость «исследовать по единой программе язык всех написанных произведений от начала письменности и [...] до нашего времени, [...] 
не пропуская ничего важного, существенного, причем на всех уровнях языка». ${ }^{1}$ Между тем, как отмечают современные исследователи, «здесь отсутствуют сколько-нибудь существенные результаты сравнительно с теми, которые были достигнуты в свое время А. В. Горским или даже И. Добровским. Это положение объясняется тем, что нет ни одного правильно изученного и изданного произведения из числа кирилло-мефодиевских переводов» (Alekseev 1984, 16).

Необходимость детального и всестороннего изучения кирилло-мефодиевского наследия была убедительно аргументирована еще во время дискуссии на IV Международном съезде славистов. В обсуждениях был поднят вопрос о построения истории церковнославянского языка как единого литературного (культурного) языка славянства. ${ }^{2}$ Однако до настоящего времени серьезное научное внимание уделяется лишь древнейшему этапу истории древнеславянского языка - языку старославянскому (выделено Е. Ш.). «Что касается изучения древнеславянских памятников более поздних эпох - вплоть до XVIII в., то они изучались, по мнению Н. И. Толстого, спорадически, и главным образом в целях обнаружения в них конкретных локальных, диалектных черт» (Tolstoi 1988, 52-53). Такое поведение исследователей относительно наследия Кирилла и Мефодия вполне объяснимо, поскольку с X - до XVIII веков продуцируется огромное количество разнообразных по содержанию и жанрам книг, написанных и напечатанных в разных культурных центрах, и в обращении находилась вся литература IX - XI веков, которая постоянно переписывалась (Kovtone 1971, 8). Как писал академик Д. С. Лихачев «изученным текстом может считаться тот, для которого создана его история» (Likhachev 1962, 481) в связи с его литературной историей: известны способы его литературного применения, сферы использования, проанализированы языковые и стилистические особенности текста, как стабильные, так изменчивые.

Для объективного описания всех этих текстов требуется системный многоязычный алгоритм для многих лингвистических фактов, где выводы о конкретных явлениях языка базируются на основании установленных связей и соотношений, представленных во многих, в идеале - во всех текстах. Исследование должно осуществляться в порядке изучения всех условий употребления той или иной словесной формы как объективного показателя реального существования и самой словесной формы, и ее значений. Огромное количество разнообразных церковнославянских письменных источников, литературные и культурные связи славян (например, восточнославянское влияние на южнославянскую письменность в XII - XIV веков (Stankov 2005, 304), «первое», «второе» и «третье» южнославянские влияния), формирование разных изводов (моравский, хорватский, болгарский, сербский и т.д.) и синкретических форм (например, «проста мова»), формирование моделей общеславянского литературного языка (Zapolskaja 2003, 83-94) делает данную программу чрезвычайно сложной для реализации.

Мы должны помнить, что церковнославянский язык длительное время стабилизировался текстом, поскольку грамматики и различные прескрипции появляются относительно поздно - в XIV веке, когда переводы, созданные Кириллом и Мефодием, уже претерпели значительную эволюцию. На протяжении столетий церковнославянский язык изучали, запоминая и заучивая тексты, а чтение церковных книг сопровождалось объяснениями и комментариями на родном понятном языке. Эти комментарии давали

1 Эта мысль, высказана Ф. П. Филиным применительно к древнерусскому литературному языку, но она, безусловно, актуальна и для исследования церковно-славянских текстов (Philin 1981, 3).

2 Смотри, например, выступления Б. Гавранека, С. А. Копорского, Б. Унбегауна, А. И. Журавского, А. Достала и др (IY International Congress 1962). 
возможность устанавливать соотношение между церковнославянскими (книжными, исходными) и родными (разговорными) формами. Именно такую стабилизацию текста наблюдаем в практике старообрядцев. Например,

- И глаголаша ему блаженный Иоанн: Послушай, отче, помилуй мя. - Иоанн то говорит: Ты, говорит, послушай, я тебя чего расскажу.

- Родители весьма мя возлюбиста паче братия моя - Меня шибко ведь родители любят-уважают [...].

- Многим бо грамотам премудрым учаще мя хотяще велий сан возвести мя. - Хочут научить меня все-таки ко грамоте, чтобы я грамотный был, чтобы выучился как следовает.

- Якоже глаголет господин мой отца болий сан хощет мя поставити и своего стратилатства посем и брак сотворити хотя. - Хочут вырастить меня, научить, а потом женить хочут, брак сотворить, вот видишь, а ведь равно не оженитса, уйдет от них и все, не узнают они, где и взеть (Nikitina 1989, 34).

Грамматики и словари, появившиеся как указывалось выше в XIV веке, описывают некий идеальный церковнославянский язык, который отражает нормализаторские устремления автора грамматики и часто не соответствует фактическому состоянию церковнославянской нормы ни в диахронии, ни в синхронии. Понять какие категории, формы, словоизменительные варианты в истории церковнославянского языка имеет то или иное слово, опираясь на данные грамматик и словарей, сложно. В церковнославянских текстах наблюдается множество орфографических и словоизменительных вариантов, региональных особенностей (и даже диалектных черт), обусловленных тем, что тексты создавались в разное время и в разной языковой среде. Имеются ошибки перевода и понимания. Например,

- в предложение Господи да не яростию обличиши насъ, ниже гневомъ твоимъ накажеши нась - глагол наказати значит 'наставить, научить, вразумить'. Между тем, некорректные переводы / толкования типа Господи, не обличи нас в ярости Твоей и не накажи нас гневом Твоим - совсем не редки.

- в предложении Господи [...] кайся не о злобахъ нашихъ, помни щедроты твои - Господи [...] сожалеющий о злобе нашей! Вспомни сострадание Твое. Глагол каятися имел в церковнославянском языке значение 'сожалеть о чем-либо', утраченное современным русским языком, что и создает трудность понимания. Существительное злоба также имело утраченное значение 'бедствие'. В таких случаях церковнославянский текст может быть восстановлен как: Господи [...] скорби о бедах наших [...].

При внимательном, строгом лингвистическом дефинировании оказывается, что толкуются не слова вообще, а конкретные лексико-семантические варианты, которые реализуются, «засвечиваются» только в окружении, то есть в связном отрезке (Marsheva 2014).

В таких случаях единственным достоверным источником о тексте является Корпус ${ }^{3}$. В настоящее время созданы и функционируют:

3 Корпус текстов (лингвистический или языковой) - это большой, представленный в машиночитаемом формате, унифицированный, структурированный, размеченный, филологически компетентный массив языковых данных, предназначенный для решения конкретных лингвистических задач. 
- церковнославянский корпус Национального корпуса русского языка (http:// ruscorpora.ru), объединяющий 1250 церковнославянских текстов и включающий около 4,6 миллионов слов, словоупотреблений и около 150 тыс. различных словоформ (Dobroshina, Poljakov 2013, 34).

- C конца 70-х годов XX века разрабатывается корпус агиографических церковнославянских текстов XVI - XVII вв. На основе картотеки житий святых русской церкви, похвальных слов, сказаний, кафедрой математической лингвистики СанктПетербургского государственного университета был создан фонд фото- и ксерокопий текстов, находящихся в разных хранилищах Петербурга, а также их электронные версии. К настоящему времени корпус охватывает 52 жития, их общий объем - более 500 тысяч словоупотреблений.

- Украинский мовно-информационный фонд НАН Украины создал электронный словарь (фактически корпус) слов и словоформ Святого письма Старого и Нового Заветов.

Для изучения наследия Кирилла и Мефодия важно, что корпус - это сформированная определенным образом выборка данных из области реализации языковой системы, базирующаяся на всех $\boldsymbol{\phi a \kappa m a x ~ и с п о л ь з о в а н и я ~ с л о в ~ и ~ г р а м м а т и ч е с к и х ~ ф о р м , ~ ф е н о м е н а х ~}$ языка, подлежащих лингвистическому описанию. В современном языкознании языковой корпус значит больше чем словари и грамматики в языкознании XX века. Поэтому, «тот язык, чье существование и изучение поддержаны специализированным лингвистическим корпусом, несомненно, имеет огромные преимущества в сохранении своего культурного потенциала перед языками, лишенными такой опоры» (Plungian 2008, 17). В отличие от любого современного литературного языка корпус данных церковно-славянского языка имеет только одно измерение - текстовое (речевое отсутствует) и главная ценность состоит в том, что он может использоваться для реконструкции церковнославянского языка как системы - это основная лингвистическая задача построения корпуса текстов огромного наследия Кирилла и Мефодия.

Возможности корпусной методологии в решении задач истории церковнославянского языка огромны:

Bo-nервых - это решение вопроса эффективного и быстрого поиска эмпирического материала. Традиционные исследовательские технологии (выборка, картотека) всегда являются достаточно трудоемкими, требуют много времени, имеют определенную долю субъективизма в отборе материала. Корпус позволяет в реальном времени обрабатывать такие массивы текстов, для которых ранее требовались месяцы и даже годы, позволяет повысить эффективность, достоверность и проверяемость данных, позволяет решать такие задачи, которые лингвистика предыдущих эпох практически не ставила в силу их трудоемкости или невыполнимости.

Церковнославянский корпус представляет собой набор текстов, размеченных в двух плоскостях. С одной стороны, каждому тексту приписана метатекстовая информация, например о названии, периоде создания, жанре, что дает возможность пользователю, получив пример на изучаемое явление, увидеть, в тексте какого типа он найден. С другой стороны - каждая словоформа в Корпусе снабжена лингвистической информацией, которая включает словарную форму (лемму), грамматические признаки и, как правило, краткое толкование. Это дает возможность поиска по лингвистическим параметрам, интересующим пользователя.

Bo-вторых, существует потенциальная возможность создания собственного пользовательского подкорпуса, в соответствии с жанрово-тематической или хронологической классификацией текстов. Исходя из принципов практического удобства, 
возможно формирование так называемых сборников. Например, «Писание» - это Библия, Служебные Евангелия и подборки паремий в богослужебных книгах, «Служба» - это все богослужебные чины и службы, а также подборки богослужебных текстов (богородичные, кондаки и т. д.) в составе разных сборников; «Право» - это тексты по церковному праву, например, «Книга Правил святых апостолов, святых соборов, вселенских и поместных, и святых отцов», «Научный» - «Ифика Иерополитика».

Поскольку вопрос о принадлежности текста к конкретному периоду истории церковнославянского языка весьма запутан, отбор текстов по времени создания важен. В существующем корпусе отсутствует поиск по конкретной дате. Значительная часть церковнославянских текстов или их сегментов создавалась и переводилась начиная c IX века, подвергались нормализаторской правке, поэтому даже «для тех текстов, где даты ясны, невозможно определить, в какой момент - в момент создания или в момент издания - производилась последняя языковая правка» (Poljakov 2016). С точки зрения языковых особенностей существенным является не время создания, а время, когда текст редактировался и приобретал вид, в котором существует. В настоящем корпусе уже представлены «архаичный», «гибридный» и «стандартный» типы церковнославянских текстов и их хронологическая привязка постоянно уточняется. Это позволит точнее изучать хронологические срезы церковнославянского языка.

B mpembux, церковнославянский язык является неоднородным по своему грамматическому строю. Одни грамматические формы могут сохранять исконный вид, другие - совпадают с формами того или иного славянского языка. Например, наряду с церковнославянской формой въ сердцы встречается форма въ сердць (характерна для восточно-славянского извода), предложный падеж множественного числа для

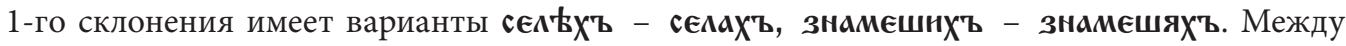
тем, процесс вытеснения церковнославянских форм формами народного языка изучен недостаточно, а для получения достоверных результатов нужна статистически значимая выборка.

Кроме того, в богослужебных текстах поздних периодов встречается значительное количество слов только формально совпадающих с формами церковнославянскими. Нарпимер, в русском языке, в том числе и в диалектной его разновидности, происходили всякого рода преобразования в словах с неполногласными формами: создание новых слов, иное их оформление, а также переосмысление и стилистическое опрощение. Бранное слово мразb, которое А. А. Шахматов приводит как пример «чистого» церковнославянизма возникает в диалектной среде, оно впервые зафиксировано в «Опыте областного словаря» 1852 г. (Vostokov A. Kh. 1852) и в современных толковых словарях обозначается как просторечное. Сравните также младше (просторечное; диалектное млаже), младменький (разговорное), сласть 'сладость' («зевнул во всю сласть» и пр. - просторечное), сласти 'кондитерские изделия, лакомства' (разговорное), сластена (разговорное; впервые в 1847 году (Dictionary of Church Slavonic 1847)), сладкоежка (то же, впервые в (Vostokov 1852)), сластоежка (то же, впервые у Даля (Dal' 1882)), благой (кричать благим матом просторечное), блажить, блажь, блажной (все просторечные) и т. д. Эти и им подобные слова не имеют отношения к наследию Кирилла и Мефодия и церковнославянскому языку как таковому.

Для истории церковнославянского языка предстоит значительная работа по выявлению неполногласных слов, восходящих непосредственно к церковнославянскому (древнеболгарскому) языку. Когда такая работа будет выполнена, станет ясно, что «история неполногласия / полногласия в славянских языках не является такой прямолинейной, как ее представляют традиционные исследования» (Prokhorova 1988, 27-28). 
Еще сложнее обстоит дело с церковнославянским суффиксально-префиксальным словообразованием, сложными словами, лексическими и семантическими славянизмами. Суффиксы -ание, -ение, -ние, -тие, -ие, -ость (-есть), -ство, -телъ, -знъ (жизнь, болезнь) и др. имелись еще в праславянском языке, из которого они были унаследованы отдельными славянскими языками, т. е. сами по себе они генетически (этимологически) не связанны с переводческой практикой Кирилла и Мефодия.

Поэтому использование корпуса позволяет отойти от описания, основанного на интуитивных суждениях исследователя. Использование корпуса церковнославянского языка - как унифицированного, структурированного, размеченного, филологически компетентного массива языковых данных - позволяет решать конкретные лингвистические задачи, формулировать законы как необходимые отношения, вытекающие из самой природы вещей (Dobroshina, Poljakov 2013, 34).

B четвертых появляется объективная возможность исследовать диахроническую вариативность грамматических категорий и конкретных лексем. Например, при запросе всех форм глагола выти Корпус выдает 119135 употреблений, слова Богъ - 43 222, из них примерно 17000 с титлом. Можно искать сочетания слов с учетом грамматических характеристик: например, по запросу «наречие + Быти» находится около 3 тысяч сочетаний типа присно сый, влйзъ сущ', свышє, єсть и подовныє. Найденные примеры на экране выглядят очень близко к классическому печатному церковнославянскому тексту, имеется возможность получить информацию о контексте, полном тексте, времени его создания, территории бытования и т.д.

В отличие от корпуса грамматики и словари церковнославянского языка не дают полной картины словоизменения. Грамматики приводят парадигмы для наиболее частотных слов, а также отдельные примеры вариативных форм. Словари обычно включают наиболее частотные или важные слова, а грамматическая информация подается фрагментарно или отсутствует. В результате нередко невозможно выяснить, какие реальные формы имеет данное слово, а спорные вопросы остаются без ответа. В корпусе словоформы не задаются априорно, а выводятся на основе анализа из множества примеров. Вариативность конкретных парадигм оказывается более разнообразной и может существенно отличаться по сравнению с представленными в грамматиках. Например, традиционное первое склонение - равъ - распадается на 14 подтипов в зависимости от конечного согласного (парный твердый-мягкий, велярный, шипящий, йот), наличия беглого гласного и других особенностей (Poljakov, 2014, 254).

B nятых корпус позволяет решить вопросы орфографии. В процессе подготовки корпуса были выработаны принципы и правила представления церковнославянских текстов, а также решены практические проблемы, касающиеся разметки и кодировки текста. Каноническая церковнославянская орфография, ориентированная на типографское представление текста, включает много символов, которые фактически не несут смыслоразличительной функции. Для представления корпуса была выработана более простая орфографическая система, которая сохраняет языковые различия, но не пытается имитировать точный типографский вид текста. В этой орфографии отсутствуют некоторые символы с малой или нулевой различительной способностью - придыхания, различие or/s, ra/g, - однако сохраняются особенности, связанные с различением лексического значения - ow, nil, өя, з3. Кроме того, были выработаны правила перевода текста из этой орфографической системы в современный вид для удобства поиска. Словоформы в корпусе представлены так же, как в исходном тексте, а леммы даются в унифицированном написании, в котором не используются избыточные буквы, а титла раскрыты (например, слово млсть рассматривается как форма к лемме милость). 
К настоящему моменту проделана значительная работа, результатом которой явилась попытка создания грамматического словаря. Проанализировано около 150 тыс. словоформ, большинству из них присвоена основная грамматическая информация: лемма, часть речи, грамматические признаки. Часть словоформ была квалифицирована как ошибки (опечатки). Для некоторых редких форм лемму определить не удалось или она была определена гипотетически.

Перспективы иерковнославянского корпуса. Чтобы корпус мог в полной мере удовлетворять потребностям современной науки в области изучения наследия Кирилла и Мефодия, исследования и преподавания церковнославянского языка, требуется его значительная доработка и развитие:

- Необходимо значительно расширить корпус текстов и включить в него памятки более ранних эпох. Несомненный интерес представляют древнейшие рукописные тексты. В настоящее время для переводческого наследия Кирилла и Мефодия факт наличия текста является фактом наличия языка. К сожалению, большинство вышедших за последние десять лет грамматик (и учебников) основаны не столько на изучении текстов, сколько на предыдущих пособиях. Реальное исследование наследия Кирилла и Мефодия возможно лишь при условии фронтального анализа функционирующих в настоящее время богослужебных текстов, с учетом особенностей конкретных изданий. Для такого анализа могут быть использованы методы корпусной лингвистики. И наиболее перспективным в этом направлении представляется разработка параллельных корпусов текстов состоящих из множества исходных оригиналов и их переводов на один или несколько языков.

- На наш взгляд, перспективным является разработка корпуса современного церковнославянского языка для изучения проблем передачи значений / смыслов в исходном церковнославянском тексте и современном. О необходимости подобного рода исследований писал В. Г. Гак, когда утверждал, что, «сравнивая переводы с подлинником, мы сплошь и рядом обнаруживаем такие лексические замены, которые не предусматриваются никакими словарями и никак не могут быть объяснены с их помощью» (Huk 1977, 68). На значительные нелепости в современных переводах церковнославянского языка указывют А. М. Камчатнов (Kamchatnov 1996; Kamchatnov 2012), И. А. Реморов (Remorov 2007, 30-32), Л. И. Маршева (Marsheva 2012), Ф. Б. Людоговский (Ljudogovskii 2001) и другие.

- Интересным направлением в области исследований наследия Кирилла и Мефодия является гипотеза о дискурсивной близости различных изводов церковнославянского языка. Именно при помощи корпусного статистического анализа возможно изучение религиозного христианского дискурса (современного и/или исторического) для решения вопроса о наличии / отсутствии общего культурного / литургического языка славянства в разные исторические эпохи. Изучение лексики религиозного христианского дискурса церковнославянского языка - т. е. языка проповедей, богословских эссе, религиозной прессы и других текстов, созданных христианами для обслуживания христианства - как отдельного пласта, который выступает маркером разграничения церковнославянских текстов от текстов на современном языке.

Существующая версия Корпуса церковнославянских текстов далека от совершенства и требует дальнейшего усовершенствования. Но даже в таком виде Корпус способен значительно ускорить работу, связанную с изучением текстов, созданных на нем, и помочь в описании церковнославянского языка. Дальнейшее развитие Корпуса 
церковнославянского языка позволит расширить представления о церковнославянском языке и употребляющихся в нем лексем, даст возможность восстановить исконное состояние языка, ликвидировать ошибки, по разным причинам попавшие в текст, а также даст возможность пользователям легче понимать содержание исконного церковнославянского текста.

\section{REFERENCES}

Alekseev, Anatoly. 1984. Переводческое наследие Кирилла и Мефодия и его исторические судьбы. Автореферат на соискание ученой степени доктор филологических наук [Translated heritage of Cyril and Methodius and their historical judgments. Abstract of Doctor of Philology]. www.dissercat.com/content/perevodcheskoe-nasledie-kirilla-i-mefodiya.

Dal', Vladimir. 1882. Толковый словарь живого великорусского языка [Explanatory dictionary of the people's great Russian language]. St. Petersburg - Moskow.

Dictionary of Church Slavonic. 1847. Словарь церковнославянского и русского языка, составленный Вторым отделением Императорской академией наук СПб. Том 3. [Dictionary of Church Slavonic and Russian languages, compiled by the Second department of the Imperial Academy of Sciences V. 3]. St. Petersburg.

Dobroshina, Catherine, Poljakov, Alexey. 2013. Корпус церковнославянского языка: возможности, методы создания, перспективы. In Вестник Православного СвятоТихоновского гуманитарного университета. Серия 3: Филология [Church Slavonic language corpus: opportunities, methods of creation, prospects In Bulletin of the Orthodox St. Tikhon Humanities University. Series 3: Philology], 32-44.

Huk, Vladimir. 1977. Сопоставительная лексикология. На материале французского и русского языков. М.: Международные отношения [Comparative lexicology. On the French and Russian languages Based. International relations]. Moscow.

Kamchatnov, Alexandr. 2012. О лингвистическом статусе церковнославянского языка. [On the linguistic status of the Church Slavonic language] / Режим доступу. http://www. philology.ru/linguistics2/ kamchatnov-96.htm.

Kamchatnov, Alexandr. 1996. Сакральный славянский язык в церкви и культуре. In Современное обновленчество - протестантизм „восточного обряда“ [Sacred Slavic language in church and culture. In Modern Renovations - Protestantism of the "Eastern Rite"]. Moscow.

Kovtone, Lilija. 1971. Русские книжники ХУІ столетия о литературном языке своего времени. In Русский язык. Источники для его изучения [Russian scribes of the XУI century about the literary language of their time. In Russian language. Sources for studying it]. Gorky.

Likhachev, Dmitrij. 1962. Основные принципы текстологического изучения памятников русской литературы XI-XVII вв.: Доклады на общем собрании Отделения литературы и языка АН СССР, 27 июня 1962 г. In Известия АН СССР. Отделение литературы и языка [Basic principles of textual study monuments of Russian literature of the XI-XVII centuries : Reports at the general meeting Department of Literature and Language of the USSR Academy of Sciences, June 27, 1962 In Izvestia of the Academy of Sciences USSR. Department of Literature and Language] 21/ 6, 481-490.

Ljudogovskii, Fedor. 2001. Актуальные проблемы изучения и преподавания современного церковнославянского языка. In Исследование славянских языков в русле традиций сравнительно-исторического и сопоставительного языкознания [Actual problems of 
researching and teaching to the modern Church Slavonic language. In Research of Slavic languages in line with the traditions of historical and comparative linguistics] Moscow, 71-74.

Marsheva, Larisa. 2012. Социолингвистика и церковнославянский язык (предварительные результаты) In Вестник православного Свято-Тихоновского гуманитарного университета. Серия 3: Филология [Sociolinguistics and Church Slavonic (preliminary results) In Bulletin of the Orthodox St. Tikhon Humanities University. Series 3: Philology], 156-160.

Marsheva, Larisa. Церковнославянский язык - мертвый или живой? [Church Slavonic - Dead or Alive?]. http://www sdsmp.ru/news/n3134/.

Nikitina, Serafima. 1989. О взаимоотношении устных и письменных форм в народной культуре (на материале полевых исследований старообрядцев) Славянский и балканский фольклор: Реконструкция древнеславянской духовной культуры [About relationship between of verbal and written forms in folk culture (on empirical research of Old Believers). Slavonic and Balkan folklore: Reconstruction of ancient Slavonic spiritual culture]. Moscow. Philin, Fedot. 1981. Истоки и судьбы русского литературного языка [The origins and destinies of the Russian literary language]. Moscow.

Plungian, Vladimir. 2008. Корпус как инструмент и как идеология: о некоторых уроках

современной корпусной лингвистики.[The corpus as a tool and as an ideology: on some lessons of modern corpus linguistics In Русский язык в научном освещении [Russian language in scientific coverage] 16/2, 7-20.

Poljakov, Alexey. Грамматический словарь церковнославянского языка (по материалам корпуса). [Church Slavonic grammar dictionary (based on corpus materials)]. Режим доступа http://dic.feb-web.ru/slavonic/dicgram.

Poljakov, Alexey. 2014. Корпус церковнославянских текстов: проблемы орфографии и грамматики Corpus of Church Slavonic texts: problems of orthography and grammar]. In Przegląd Wschodnioeuropejski 5/1, 245-254.

Poljakov, Alexey, Dobroshina, Catherine R., Ivanova-Allenova, Tanjana. 2013. Корпус церковнославянских текстов в составе НКРЯ, первая версия: проблемы и решения. In Вестник Православного Свято-Тихоновского гуманитарного университета. Серия 3: Филология [Corpus of Church Slavonic texts as part of the National Corps of the Russian Language, the first version: problems and solutions. In Bulletin of the Orthodox St. Tikhon Humanities University. Series 3: Philology], 32-44.

Prokhorova, Olga. 1988. Полногласие и неполногласие в русском литературном языке и народных говорах [Pleophonic and non-Pleophonic in the Russian literary language and folk dialects]. Leningrad.

Remorov, Ivan. 2007. Практическая аксиология церковнославянского языка. Вестник Православного Свято-Тихоновского гуманитарного университета. Серия 3: Филология [Practical axiology of the Church Slavonic language In Bulletin of the Orthodox St. Tikhon Humanities University. Series 3: Philology], 23-32.

Stankov, Rastislav. 2005. Так называемое восточнославянское влияние на южнославянскую письменность в XII-XIV вв. и проблема древнейших славянских переводов с греческого [The so-named East Slavonic influence on the South Slavonic book writing in the XII-XIV centuries and the problem of oldest Slavonic translations from Greek] In Преславска книжовна школа [Preslavska book school] 8, 304-327.

Tolstoj, Nikita. 1988. История и структура славянских литературных языков History and structure of Slavonic literary languages]. Moscow. 
Vostokov, Alexandr Kh. 1852. Опыт областного великорусского словаря, изданный Вторым отделением Академии наук [Experience of the regional great Russian dictionary, published by the Second Branch of the Academy of Sciences]. St. Petersburg.

Zapolskaja, Natalija. 2003. «Общеславянский» литературный язык: модели Ю. Крижанича и М. Маяра. In Славяноведение 1 ["Common» Slavonic literary language: models of Y. Krizhanich and M. Mayar. In Slavic studies 1], 83-94.

IY International Congress. 1962. IY Международный съезд славистов. Материалы дискуссии [IY International Congress of Sadist's. Discussion materials]. Moscow.

prof. Elena Shimko, PhD.

St. Kirill and Methodius Theological Academy

St. Goydy 4

88000 Uzgorod

Ukraine

lenashimko26@gmail.com 